\title{
Synaptic Vesicles: Test for a Role in Presynaptic Calcium Regulation
}

\author{
Greg T. Macleod, Leo Marin, Milton P. Charlton, and Harold L. Atwood \\ Department of Physiology, University of Toronto, Toronto, Ontario, M5S 1A8, Canada
}

Membrane-bound organelles such as mitochondria and the endoplasmic reticulum play an important role in neuronal $\mathrm{Ca}^{2+}$ homeostasis. Synaptic vesicles (SVs), the organelles responsible for exocytosis of neurotransmitters, occupy more of the volume of presynaptic nerve terminals than any other organelle and, under some conditions, can accumulate $\mathrm{Ca}^{2+}$. They are also closely associated with voltage-gated $\mathrm{Ca}^{2+}$ channels (VGCCs) that trigger transmitter release by admitting $\mathrm{Ca}^{2+}$ into the nerve terminal in response to action potentials (APs). We tested the hypothesis that SVs can modulate $\mathrm{Ca}^{2+}$ signals in the presynaptic terminal. This has been a difficult question to address because neither pharmacological nor genetic approaches to block $\mathrm{Ca}^{2+}$ permeation of the $\mathrm{SV}$ membrane have been available. To investigate the possible role of SVs in $\mathrm{Ca}^{2+}$ regulation, we used imaging techniques to compare $\mathrm{Ca}^{2+}$ dynamics in motor nerve terminals before and after depletion of SVs. We used the temperature-sensitive Drosophila dynamin mutant shibire, in which SVs can be eliminated by stimulation. There was no difference in the amplitude or time course of $\mathrm{Ca}^{2+}$ responses during high-frequency trains of APs, or single APs, in individual presynaptic boutons before and after depletion of SVs. SVs have a limited role, if any, in the rapid sequestration of $\mathrm{Ca}^{2+}$ within the neuronal cytosol or the synaptic microdomain. We also conclude that SVs are not important for regulation of synaptic VGCCs.

Key words: calcium regulation; calcium channels; synaptic vesicles; Drosophila; temperature-sensitive mutant; shibire

\section{Introduction}

In presynaptic nerve terminals, synaptic vesicles (SVs) occupy a larger volume than any other intracellular organelle. Apart from their principal role in sequestering and releasing transmitter substances, data from in vitro studies indicate that SVs may also participate in $\mathrm{Ca}^{2+}$ sequestration (Israel et al., 1980; Michaelson et al., 1980; Rephaeli and Parsons, 1982; Gonçalves et al., 1998). In addition, voltage-gated $\mathrm{Ca}^{2+}$ channels (VGCCs), which respond to depolarization by admitting $\mathrm{Ca}^{2+}$ close to sites of exocytosis in the synaptic active zone (Catterall, 2000), may be regulated through interactions with SVs. If SVs are significantly involved in such activities, they should modify the amplitude and kinetics of changes in the presynaptic free $\mathrm{Ca}^{2+}$ concentration $\left(\left[\mathrm{Ca}^{2+}\right]_{\mathrm{i}}\right)$ after action potentials (APs). To test this hypothesis, we compared $\mathrm{Ca}^{2+}$ transients in motor nerve terminals depleted of SVs with $\mathrm{Ca}^{2+}$ transients in nondepleted terminals.

To deplete nerve terminals of SVs, we used the Drosophila temperature-sensitive dynamin mutant shibire (Chen et al., 1991; van der Bliek and Meyerowitz, 1991), in which SVs do not recycle at temperatures above $29^{\circ} \mathrm{C}$ (the "nonpermissive" temperature) (Koenig and Ikeda, 1983; Koenig and Ikeda, 1989). Previous

Received Dec. 5, 2003; revised Jan. 20, 2004; accepted Jan. 20, 2004.

This study was supported by grants from the Canadian Institutes for Health Research (G.T.M., M.P.C., H.L.A.) and from the Natural Sciences and Engineering Research Council of Canada (H.L.A.). We are grateful to Ken DawsonScully for assistance with depletion experiments, to Philip Francis for collection and analysis of behavioral data, to Chris Gergely for performing the fura-dextran calibration, to Amin Kay for analysis of $\mathrm{Ca}^{2+}$-imaging data, to Mingshan Xue for helpful discussions, and to Marianne Hegström-Wojtowicz for managing Drosophila stocks and for help with manuscript preparation.

Correspondence should be addressed to Dr. G. T. Macleod, Department of Physiology, 1 Kings College Circle, University of Toronto, Toronto, Ontario M5S 1A8, Canada. E-mail: greg.macleod@utoronto.ca.

DOI:10.1523/JNEUROSCI.5372-03.2004

Copyright $\odot 2004$ Society for Neuroscience $\quad$ 0270-6474/04/242496-10\$15.00/0 work on this mutant concluded that nerve-evoked $\mathrm{Ca}^{2+}$ signals disappear entirely from shibire nerve terminals depleted of SVs at nonpermissive temperatures (Umbach et al., 1998). This was taken to indicate that SVs must be present for VGCCs to operate properly. The close association between VGCCs and SVs observed in detailed electron microscope tomographic reconstructions of the amphibian neuromuscular junction (NMJ) (Harlow et al., 2001) lends support to this view. Alternatively, this association may ensure rapid transmitter release independently of any modulation of the VGCCs by SVs.

The evidence that SVs sequester $\mathrm{Ca}^{2+}$ in situ is unclear. Although there have been numerous proposals of a role for SVs in presynaptic $\mathrm{Ca}^{2+}$ regulation, these are based on data from in vitro studies using cytochemical, electrophysiological, and biochemical procedures. For instance, in thin sections of neuronal tissue, electron spectroscopic imaging shows a higher concentration of calcium in the lumen of SVs than in the cytosol (Torpedo nerve electroplaque synapse, Parducz and Dunant, 1993; rat brain, Mizuhira and Hasegawa, 1997; frog NMJ, Pezzati and Grohovaz, 1999). Other studies show that there is an increase in the proportion of $\mathrm{Ca}^{2+}$-containing SV s after nerve stimulation (rat superior cervical ganglion, Parducz et al., 1987; Torpedo, Parducz and Dunant, 1993, Parducz et al., 1994). Ion channels in the SV membranes may allow $\mathrm{Ca}^{2+}$ entry (for review, see Rahamimoff et al., 1990; Woodbury, 1995). A Ca ${ }^{2+}-\mathrm{H}^{+}$exchange has been demonstrated in SV membranes in which elevated $\mathrm{Ca}^{2+}(\sim 500 \mu \mathrm{M})$ induced $\mathrm{H}^{+}$release from SVs isolated from sheep brain cortex (Gonçalves et al., 1998). In addition, a high-affinity ATPdependent $\mathrm{Ca}^{2+}$ pump takes up $\mathrm{Ca}^{2+}$ in isolated SVs (Torpedo electric organ synapses, Israel et al., 1980; Michaelson et al., 1980; Rephaeli and Parsons, 1982). Thus, although $\mathrm{Ca}^{2+}$ can be found concentrated in SVs, and SVs accumulate $\mathrm{Ca}^{2+}$ under some cir- 
cumstances, it remains to be demonstrated that SVs can influence $\left[\mathrm{Ca}^{2+}\right]_{\mathrm{i}}$ regulation in an intact nerve terminal. If $\mathrm{SV}$ s sequester $\mathrm{Ca}^{2+}$ in Drosophila nerve terminals under conditions of elevated $\left[\mathrm{Ca}^{2+}\right]_{\mathrm{i}}$, their absence should alter the amplitude and time course of $\mathrm{Ca}^{2+}$ signals during stimulation.

The experiments reported here were designed to test the need for $\mathrm{SVs}$ in $\mathrm{Ca}^{2+}$ entry and regulation during stimulation. By completely depleting SVs in shibire nerve terminals, we were able to test two previous hypotheses: (1) SVs are required for VGCC function; and (2) SVs sequester $\mathrm{Ca}^{2+}$ during and after nerve impulses, thereby modifying the amplitude and/or time course of the changes in $\left[\mathrm{Ca}^{2+}\right]_{\mathrm{i}}$. We found that elimination of intraterminal SVs by stimulating shibire motor nerves at nonpermissive temperatures had little impact on the intracellular $\mathrm{Ca}^{2+}$ signal.

\section{Materials and Methods}

Fly stocks. All experiments were performed on wandering third instar larvae of Drosophila melanogaster. The Drosophila mutant shibire [temperature-sensitive allele $1\left(s h i^{t s I}\right)$, referred to henceforth as shi] was originally generated by ethyl methanesulfonate mutagenesis of Oregon Red (OR) flies (Grigliatti et al., 1973). OR flies were used here as the wild-type control. Canton Special (CS) and shi strains were gifts from Dr. K. E. Zinsmaier (University of Arizona, Tucson, AZ), and the $O R$ strain was a gift from Dr. M. L. Suster (McGill University, Montreal, Quebec, Canada). All fly stocks were kept in noncrowded conditions at $22 \pm 1^{\circ} \mathrm{C}$ on cornmeal agar with dry yeast.

Larval movement assay. A custom-built apparatus was used to monitor the movement of shi, OR, and CS larvae during temperature cycles between 22 and $34^{\circ} \mathrm{C}$ (see Fig. 1). Five third instar larvae were placed on a flat agarose gel substrate in a circular chamber $(60 \mathrm{~mm}$ in diameter, $3 \mathrm{~mm}$ deep) formed on the upper surface of a fan-cooled Peltier device (Tellurex, Traverse City, MI). A transparent heater (Minco Products, Minneapolis, MN) closed the top of the chamber, facilitating rapid increases in temperature. To alter the temperature of the chamber from 22 to $34^{\circ} \mathrm{C}$ and back to $22^{\circ} \mathrm{C}$, we controlled the current in Peltier device and heater by a temperature controller (model 5C7-362; Oven Industries, Mechanicsburg, PA) and feedback thermistor. Changes in the controller set point were made by a computer program via a serial port on the controller that also recorded the real temperature in a disk file. This system was designed to produce rapid and reproducible changes in temperature. Video images of larvae were obtained with a standard monochrome CCD camera (MK-1312E; Marscam, Taipei, Taiwan). A record of the larval positions was captured at 5 sec intervals on a personal computer through a frame-grabber board (DT3155' Data Translation, Marlboro, MA) supported by AIW 4.0 software (Axon Instruments, Union City, CA). A pixel-by-pixel subtraction of consecutive images using ImageJ software (http://rsb.info.nih.gov/ij/) provided a measure of relative movement calculated for $5 \mathrm{sec}$ intervals over the entire $1 \mathrm{hr}$ period. Four trials were averaged for each strain to produce records of larval movement over the temperature cycle (see Fig. 1).

The larval NMJ preparation and temperature control. Larvae were dissected in chilled Schneider's insect medium (Schneider's) (Sigma, St. Louis, MO) to make a filleted preparation pinned to the Sylgard (Dow Corning, Midland, MI) base of a $0.5 \mathrm{ml}$ perfusion bath. All nerves issuing from the ventral ganglion were severed. Before $\mathrm{Ca}^{2+}$ imaging, Schneider's was replaced with physiological solution [Hemolymph-Like number 6 (HL6)] (Macleod et al., 2002) that continuously superfused the preparation, except in fura-dextran (fura) imaging experiments in which HL6 was renewed at least every $30 \mathrm{~min}$. $\left[\mathrm{Ca}^{2+}\right]_{\mathrm{o}}$ and $\left[\mathrm{Mg}^{2+}\right]_{\mathrm{o}}$ in HL6 were 0.5 and $15 \mathrm{~mm}$, respectively, or, when specifically indicated, 2 and 4 $\mathrm{mm}$, respectively. The temperature of the preparation was controlled by the flow of HL6 superfusate $(3 \mathrm{ml} / \mathrm{min})$ that was heated over a Peltier device (Melcor, Trenton, NJ), connected to an adjustable $6 \mathrm{~V}$ DC power supply. To obtain adequate temperature control, the thermally conductive aluminum nose cone of the water-immersion objective $(40 \times, 0.55$ numerical aperture, $160 \mathrm{~mm}$; Nikon, Tokyo, Japan) was replaced with a custom-made Delrin nose cone that is much less thermally conductive than the standard aluminum nose cone. Two thermocouples, $2 \mathrm{~mm}$ apart on either side of a larva, were used to monitor the bath temperature.
Loading calcium indicators into motor neuron terminals. Motor neurons (MNs) of the longitudinal abdominal muscles were forward filled with $10 \mathrm{kDa}$ dextran conjugates of Oregon Green 488 BAPTA-1 (OGB-1) $\left[\mathrm{Ca}^{2+}\right.$ dissociation constant $\left.\left(K_{\mathrm{d}}\right), 454 \mathrm{nM}\right]$ or fura $\left(K_{\mathrm{d}}, 594 \mathrm{~nm}\right.$, measured in $100 \mathrm{~mm} \mathrm{KCl}$ and $30 \mathrm{~mm}$ MOPS) (Molecular Probes, Eugene, OR) dissolved in water, using the method described by Macleod et al. (2002). Dextran-conjugated $\mathrm{Ca}^{2+}$ indicators were used because they are not taken up by intracellular organelles. OGB-1 $10 \mathrm{kDa}$ dextran was used because it is visible at resting $\left[\mathrm{Ca}^{2+}\right]_{\mathrm{I}}$ and has a $K_{\mathrm{d}}$ well matched to the $\left[\mathrm{Ca}^{2+}\right]_{\mathrm{i}}$ range we wanted to observe and a good dynamic range. It also appears to have little impact on the time course of the $\mathrm{Ca}^{2+}$ signal decay after short trains of pulses at $20 \mathrm{~Hz}$, or single APs, in Drosophila motor neuron terminals. This was ascertained by comparing $\mathrm{Ca}^{2+}$ signals in the presence of OGB-1 and the low-affinity indicator Fluo-4 $10 \mathrm{kDa}$ dextran (Macleod et al., 2002). To load indicators, a hemisegment nerve was cut close to the ventral ganglion and then drawn by suction into the end of a heat-polished glass pipette $(\sim 12 \mu \mathrm{m}$ diameter $)$ to form a fit just tight enough to exclude further entry of Scheider's from the preparation bath. A fine plastic tube was introduced into the suction pipette to apply the indicator, at a final concentration of 0.5-2 mM in Schneider's, to the cut end of the nerve; this was done within 5 min after cutting the nerve. After $20-40 \mathrm{~min}$, the fine plastic tube was used to flush the indicator from the tip of the pipette with fresh Schneider's. The suction pipette, now filled with Schneider's, was left in place as the anode for stimulating the nerve.

Calcium imaging with Oregon Green 488 BAPTA-1. Imaging of OGB1-loaded $\mathrm{MN}$ terminals was performed on a Nikon microscope (Optiphot-2) fitted with a Bio-Rad-600 confocal scan head (Bio-Rad, Mississauga, Ontario, Canada). Only type-1b boutons on muscles 6 and 7 were examined. To reduce phototoxicity, the argon ion laser was operated at low power, and the output was attenuated to $0.5 \%$ by neutral density filters. A light-emitting diode inserted into the optical path via a side inspection port of the scan head was lit for 2 msec to mark the first pulse in stimulation trains. Scanned images were saved in eight-bit PIC format and then converted to TIFF format for analysis using ImageJ software. Both frame scans (for whole-bouton measurements) and line scans (for higher temporal resolution of $\mathrm{Ca}^{2+}$ changes within a single bouton) were collected as described by Macleod et al. (2002). The principle for analyzing frame scan data were the same as for analyzing line scan data. Average pixel values were measured within selected regions of each image, or each line, and also in an adjacent region not containing any OGB-1 fluorescence to provide a background value. This background value was subtracted numerically from the average pixel value of the fluorescence-containing region to generate the fluorescence value $(F)$. Images of fluorescence are shown without the background subtracted. $\Delta F / F_{\mathrm{R}}$ is calculated by dividing the change in $F$ in response to stimulation $(\Delta F)$ by the value of $F$ at rest $\left(F_{\mathrm{R}}\right)$ before nerve stimulation (see Figs. $3 D, 4 B, 5,6,7 C, 8) . \Delta F / F_{\mathrm{S}}$ is calculated by dividing the change in $F$ in response to the cessation of stimulation $(\Delta F)$ by the value of $F$ during nerve stimulation $\left(F_{\mathrm{S}}\right)$ (see Fig. $3 B$ ). All estimates of the time course of decay were made using Sigma Plot (SPSS, Chicago, IL) by fitting a single-exponential curve to line scan data.

Calcium imaging with fura-dextran. Imaging of fura-dextran-loaded nerve terminals was performed on a Nikon (Optiphot-2) microscope with an Olympus Optical (Tokyo, Japan) water-immersion objective ( $40 \times, 0.7$ numerical aperture). The microscope was fitted with an intensified CCD camera (model IC-100; PTI, Princeton NJ) and a filter wheel (model 5240; Pacific Scientific, Metaltek Instruments, Raleigh, NC) controlled by an Axon Instruments (Foster City, CA) Digidata 2000 frame grabber supported by AIW 2.2 software. Images were acquired through a $530 \pm 35 \mathrm{~nm}$ bandpass filter as a mercury arc lamp was used to illuminate the preparation alternately through $340 \pm 5$ and $380 \pm 5 \mathrm{~nm}$ bandpass filters (Omega Optical, Brattlebro, VT). Equation 5 by Grynkiewicz et al. (1985) was used to calculate $\left[\mathrm{Ca}^{2+}\right]_{\mathrm{i}}$ values. Values of $R_{\min }$ and $R_{\max }$ were obtained in situ through bath application of $1 \mathrm{~mm}$ ionomycin (Calbiochem, La Jolla, CA) in HL6 containing either no added $\mathrm{Ca}^{2+}$ and 10 mM EGTA $\left(R_{\min }\right.$; Sigma) or $10 \mathrm{~mm}\left[\mathrm{Ca}^{2+}\right]_{\mathrm{o}}\left(R_{\max }\right)$ (both solutions were adjusted to $\mathrm{pH} 7.2$ using $\mathrm{NaOH}$ ). The $\mathrm{Ca}^{2+}$ dissociation constant has not been determined for fura-dextran in Drosophila MNs in situ. The value 
determined in situ for fura-2 in crayfish MNs $\left(K_{\mathrm{d}}, 865 \mathrm{~nm}\right)$ (Tank et al., 1995) has been used in this study.

The use of L-glutamic acid to reduce muscle contraction. High-frequency stimulation of MNs at physiological levels of $\left[\mathrm{Ca}^{2+}\right]_{0}$ results in significant $\mathrm{Ca}^{2+}$ influx, considerable neurotransmitter release, and corresponding muscle contraction, which interferes with $\mathrm{Ca}^{2+}$ imaging. To overcome the problem of muscle contraction at $\mathrm{MN}$ terminals not depleted of SVs, we added L-glutamic acid (LGA) to the HL6 superfusate. We found that glutamate receptors become sufficiently desensitized, at millimolar concentrations of LGA ( $\geq 5 \mathrm{~mm}$ ), to allow $80 \mathrm{~Hz}$ stimulation of the nerve without muscle contraction $\left(0.5\right.$ or $\left.2 \mathrm{~mm}\left[\mathrm{Ca}^{2+}\right]_{\mathrm{o}}\right)$. Stimulation trains of 80 pulses at $80 \mathrm{~Hz}$ were chosen to test the $\mathrm{Ca}^{2+}$ handling properties of MN terminals during activity because this paradigm resembles MN activity during fictive locomotion (Cattaert and Birman, 2001; Barclay et al., 2002). We examined the amplitude of OGB-1 fluorescence transients evoked during $10 \mathrm{~Hz}$ stimulation in shi MN terminals in the presence of $7 \mathrm{~mm}$ LGA and found no difference (paired $t$ test; $p=0.78$ ) relative to the amplitude of transients in its absence $\left(\Delta F / F_{\mathrm{R}}\right.$ of $28.2 \pm$ $8.5 \%$ with and $29.3 \pm 6.3 \%$ without; $n=5$ ). The relationship between the frequency of stimulation and $\Delta F / F_{\mathrm{R}}$ in the presence of $7 \mathrm{~mm}$ LGA was linear in the $10-80 \mathrm{~Hz}$ range (data not shown), and $80 \mathrm{~Hz}$ stimulation did not result in dye saturation because 120 and $160 \mathrm{~Hz}$ stimulation always resulted in significantly greater changes in OGB-1 fluorescence, often with muscle contraction (data not shown).

Protocol to deplete MN terminals of SVs. Larval preparations intended for depletion treatment were heated by superfusing HL6 with increased $\left[\mathrm{Ca}^{2+}\right]_{\mathrm{o}}(2 \mathrm{mM})$ and reduced $\left[\mathrm{Mg}^{2+}\right]_{\mathrm{o}}(4 \mathrm{mM})$ to maximize transmitter release during stimulation (see Fig. $4 \mathrm{~A}$ ). After $3 \mathrm{~min}$ at $34 \pm 1{ }^{\circ} \mathrm{C}$, the segmental nerve was stimulated at $30 \mathrm{~Hz}$ for $6 \mathrm{~min}$ (10,800 pulses). Periodic inspection of the OGB-1 fluorescence level within the boutons indicated that APs were being continually delivered to type-1b boutons throughout the impulse train. If the stimulus voltage was reduced below a certain threshold at any time during the train, the fluorescence level dropped immediately. Thus, depletion-inducing stimulation was effective in activating boutons throughout the entire period of stimulation.

Electron microscopic examination of terminal boutons, subsequent to stimulation, was used to verify complete depletion of SVs. Electrophysiological methods were not used to attempt verification, because the signs of SV depletion [the inability to evoke excitatory junction potentials (EJPs) and the inability to detect miniature EJPs (mEJPs)] can occur without SV depletion. The inability to evoke EJPs is not proof of SV depletion because one or both motor axons innervating muscle 6 or 7 can become inexcitable (especially at high temperatures) before SV depletion occurs. Although mEJPs may go undetected for a period, a combined electron microscopical and electrophysiological study has demonstrated previously that numerous SVs can occupy the active zones of shibire terminal boutons while mEJPs are very infrequent (Koenig and Ikeda, 1999).

Electron microscopy. Filleted larval preparations were fixed within minutes of depletion stimulation in a preheated mixture $\left(34^{\circ} \mathrm{C}\right)$ of $3 \%$ glutaraldehyde, $1 \%$ formaldehyde, and $0.1 \mathrm{M}$ sodium cacodylate buffer at $\mathrm{pH}$ 7.2 for $4 \mathrm{hr}$. After fixation, preparations were rinsed in the same buffer for $2 \mathrm{hr}$ at $4^{\circ} \mathrm{C}$ and then trimmed to allow unambiguous identification of the stimulated segment. Preparations were postfixed in $1 \%$ osmium tetroxide for $1 \mathrm{hr}$, followed by tissue dehydration in a graded ethanol series $(30-100 \%, 20 \mathrm{~min})$ and propylene oxide. The preparation was infiltrated and embedded with Epon-Araldite for $2 \mathrm{~d}$ at $60^{\circ} \mathrm{C}$. Sections of $75 \mathrm{~nm}$ were cut on a Reichert-Jung ultracut microtome, stained with uranyl acetate and lead citrate, examined in a Hitachi (Tokyo, Japan) H-7000 transmission electron microscope, and photographed with an AMT Advantage HR/HR-B CCD camera system (Advanced Microscopy Techniques, Danvers, MA).

\section{Results}

If SVs are substantially involved in the regulation of $\mathrm{Ca}^{2+}$ channels or the sequestration of $\mathrm{Ca}^{2+}$, stimulus-dependent $\mathrm{Ca}^{2+}$ signals would be altered in the absence of SVs. To test this prediction, we developed a protocol to deplete MN terminals of SVs in shi larvae without permanently compromising cellular physiology.
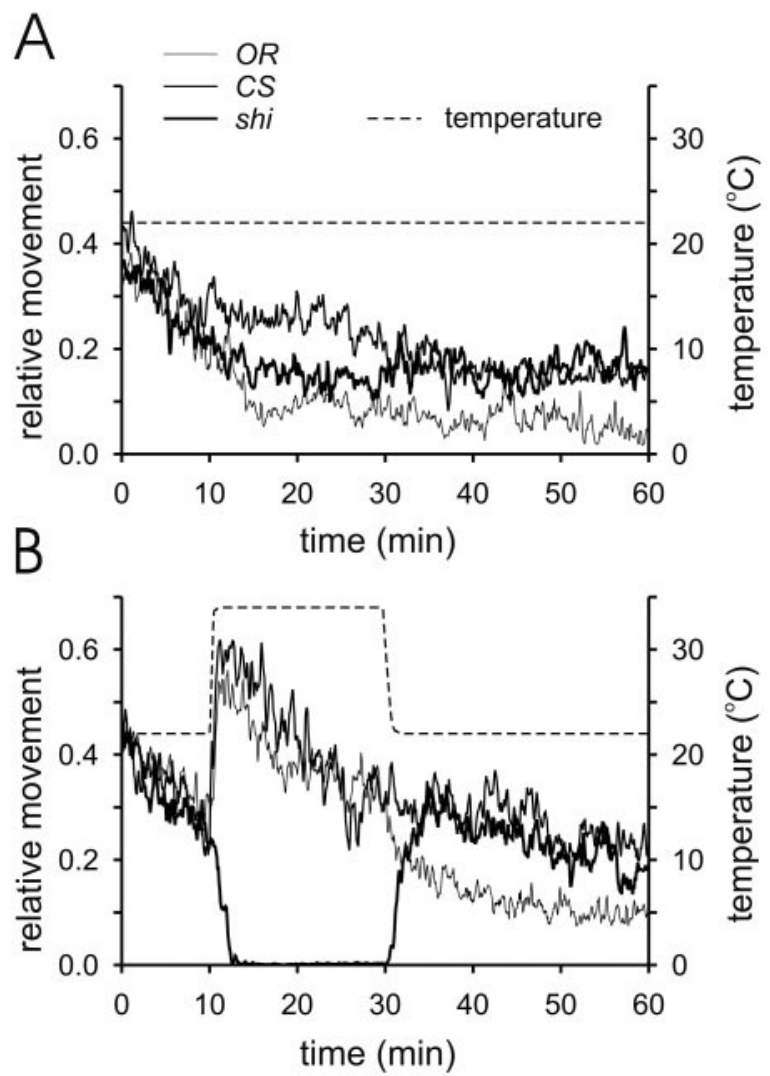

Figure 1. Activity of shi, $O R$, and CS larvae was similar at room temperature, but shi larvae exhibited reversible paralysis at a nonpermissive temperature. $A$, Average relative movement of larvae over a 60 min period at a constant temperature of $22^{\circ} \mathrm{C}$. Each jagged trace (plotted against the left ordinate) represents the average of four trials of five larvae, smoothed with a three-point moving average. $B$, Average relative movement of larvae during a stepped temperature cycle, from $22^{\circ} \mathrm{C}$ up to $34^{\circ} \mathrm{C}$ and back down to $22^{\circ} \mathrm{C}$. Temperature is indicated by the right ordinate. Time $=0$ (minutes) corresponds to $\sim 10 \mathrm{~min}$ after the larvae were placed in the chamber.

\section{shi larvae are paralyzed at $34^{\circ} \mathrm{C}$ but recover rapidly when cooled}

We first tested shi larvae for temperature-dependent paralysis and recovery. Delgado et al. (2000) established that larval MN terminals can be depleted of SVs by stimulating the nerve while holding the preparation at $34^{\circ} \mathrm{C}$. We wanted to hold MN terminals at this nonpermissive temperature long enough to deplete them of SVs and then collect physiologically valid data from them. However, previous studies had indicated that shi flies recover very slowly, if at all, from extended exposures to nonpermissive temperatures (see Fig. 3) (Siddiqi and Benzer, 1976). To establish that shi larvae are capable of recovery, we monitored the activity of larvae while the temperature was cycled from 22 to $34^{\circ} \mathrm{C}$ and back to $22^{\circ} \mathrm{C}$ (Fig. 1). The positions of shi, OR, and CS larvae were monitored at $5 \mathrm{sec}$ intervals, and a measure of movement was calculated (see Materials and Methods). At room temperature $\left(22^{\circ} \mathrm{C}\right)$, all strains of larvae showed gradual reduction in activity over a $1 \mathrm{hr}$ test period (Fig. $1 \mathrm{~A}$ ). When the temperature was elevated to $34^{\circ} \mathrm{C}$, both $O R$ and $C S$ strains became more active, whereas the shi strain stopped moving within $3 \mathrm{~min}$ (Fig. $1 \mathrm{~B}$ ). When, after $20 \mathrm{~min}$ at $34^{\circ} \mathrm{C}$, the temperature was reduced to $22^{\circ} \mathrm{C}$, shi larvae began moving again and regained a level of activity comparable with $O R$ and $C S$ strains within $5 \mathrm{~min}$.

The resumption of movement by shi larvae shown in Figure 1 indicates that normal physiology is restored after extended expo- 
sure to $34^{\circ} \mathrm{C}$. From these behavioral data, we cannot assume that the MN terminals are fully depleted coincident with paralysis, because paralysis may result from depletion of SVs at central synapses (Kosaka and Ikeda, 1983). However, in shi adults, some MN terminals become depleted of SVs if the nerves are not severed from the CNS at nonpermissive temperatures (Kawasaki et al., 2000). Thus, it is likely that the $\mathrm{MN}$ terminals in freely moving shi larvae, exposed to $34^{\circ} \mathrm{C}$, recover from at least a partial depletion of SVs.

\section{Evidence of synaptic vesicle depletion}

Up to 4000 pulses are required to deplete shi larval MN terminals in an isolated preparation at $34^{\circ} \mathrm{C}$ (Delgado et al., 2000), whereas stimulation below $30 \mathrm{~Hz}$ is insufficient to deplete the reserve pool of SVs (Kuromi and Kidokoro, 2000). Because our MN terminals were loaded with OGB-1 and because similar $\mathrm{Ca}^{2+}$ chelating compounds can compete for $\mathrm{Ca}^{2+}$ with the $\mathrm{Ca}^{2+}$ sensor for transmitter release and thus inhibit release of SVs (Adler et al., 1991), we stimulated at a higher frequency than in previous studies; high-frequency stimulation can overcome the effects of modest concentrations of chelators (Winslow et al., 1994).

Filleted shi larval preparations were heated with superfusing HL6, and, after $3 \mathrm{~min}$ at $34 \pm 1^{\circ} \mathrm{C}$, the segmental nerve was stimulated at $30 \mathrm{~Hz}$ for $6 \mathrm{~min}$ (10,800 pulses); release was maximized by the inclusion of $2 \mathrm{mM}\left[\mathrm{Ca}^{2+}\right]_{\mathrm{o}}$ and $4 \mathrm{~mm}\left[\mathrm{Mg}^{2+}\right]_{\mathrm{o}}$ in the HL6. To determine that they were depleted of SVs, we examined stimulated boutons by electron microscopy and compared them with unstimulated boutons in the same preparation. Within minutes of the end of the stimulus train and without allowing the temperature to drop, we replaced HL6 with a preheated mixture $\left(34^{\circ} \mathrm{C}\right)$ of $3 \%$ gluteraldehyde and $1 \%$ formaldehyde. The preparation was then processed for thin-section $(75 \mathrm{~nm})$ transmission electron microscopy (see Materials and Methods). We note that it is unlikely that the application of fixative alone causes significant exocytosis, because exocytosis subsides within $500 \mathrm{msec}$ of fixative application at the adult coxal muscle NMJ (Koenig et al., 1998) and within $1 \mathrm{sec}$ at rodent hippocampal synapses in culture (Rosenmund and Stevens, 1997).

Serial sections of type- $1 \mathrm{~b}$ boutons in unstimulated segments adjacent to the stimulated segment were filled with SVs (Fig. $2 \mathrm{~A}$ ). In contrast, the boutons in the stimulated segment were completely devoid of SVs (Fig. 2 B, C). All 18 sections from the stimulated boutons were examined, and no SVs could be identified. Sac-like membranous inclusions of variable size were present, and these internalized sacs were often confluent with the extracellular space (Fig. 2D). Mitochondria in the stimulated boutons appeared normal, indicating that gross changes in $\left[\mathrm{Ca}^{2+}\right]_{i}$ or osmotic pressure had not occurred. Although no SVs were found in $\mathrm{MN}$ terminal boutons stimulated at $34^{\circ} \mathrm{C}$, larger vesicular structures arrested in the process of pinching off from the surface were observed. Some had electron-dense "necks" at their point of contact with the surface plasma membrane (PM). This feature has been observed in previous electron microscopy of dynamin mutants (Kosaka and Ikeda, 1983, 1989).

\section{$\mathrm{Ca}^{2+}$ accumulation in presynaptic boutons during and after depletion of SVs}

To confirm that MN terminals were continuously stimulated during depletion, we measured OGB-1 fluorescence as an indicator of $\left[\mathrm{Ca}^{2+}\right]_{\mathrm{i}}$. Elevated OGB-1 fluorescence during the stimulus train and its decline on cessation of stimulation is a good indicator of effective bouton excitation during our depletion trains. Images of OGB-1-loaded boutons were acquired with a laserscanning confocal microscope every $680 \mathrm{msec}$ as the depletion
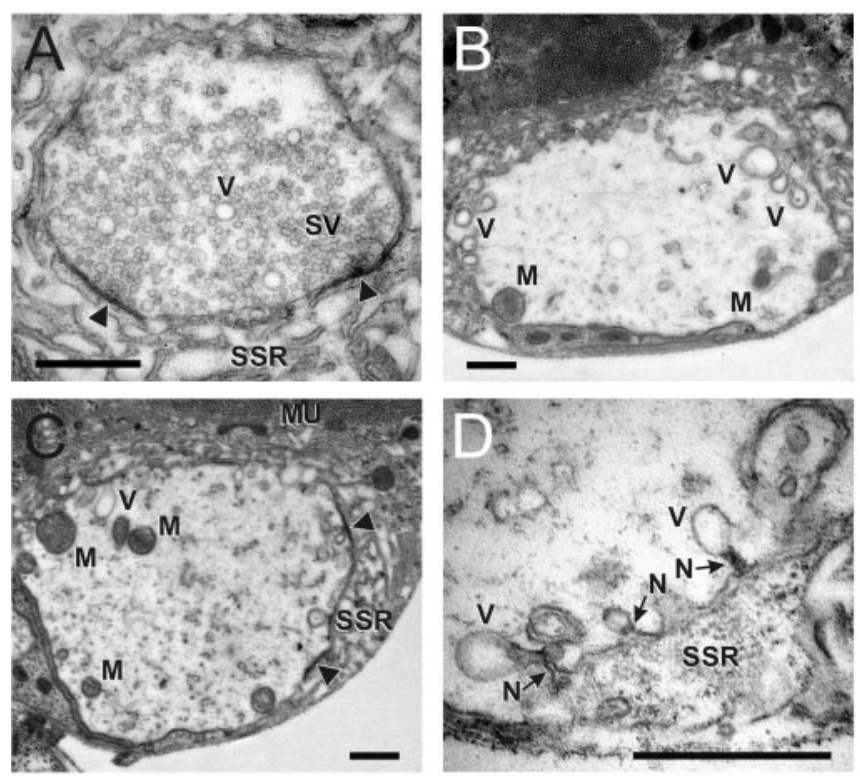

Figure 2. Stimulation at nonpermissive temperatures leads to complete depletion of synaptic vesicles in nerve terminals of shi larvae. Thin section electron micrographs. $A$, Type-1b bouton in segment 2 (nonstimulated) with full complement of SVs, fixed after $\sim 10$ min at $34^{\circ} \mathrm{C}$. Two synaptic contacts (arrowheads) are present, contacting processes of the subsynaptic reticulum (SSR), which is an extension of the muscle fiber (MU). A few large vesicles (V) are disbursed among the SVs. B, C, Similar type-1b boutons in segment 3 (muscle 6/7) of the same preparation, loaded with OGB-1 and depleted of SVs by stimulating the segmental nerve at $30 \mathrm{~Hz}$ for 6 min. Numerous prominent vesicles (V) appear near the presynaptic bounding membrane; mitochondria (M) appear normal. No SVs were found anywhere in the presynaptic terminal. $D$, Higher magnification to illustrate membranous structures issuing from the plasma membrane of a depleted type- $1 \mathrm{~b}$ bouton. Sac-like structures of variable morphology remain confluent with the extracellular space. Several prominent electron-dense necks $(N)$ are evident at the junction of sac-like vesicular structures $(V)$ and the surface membrane. Scale bars, $0.5 \mu \mathrm{m}$.

stimulation train ended (Fig. 3A,B). OGB-1 fluorescence dropped immediately on cessation of stimulation between one image (Fig. 3A, third image) and the next (fourth image). The average fluorescence for five preparations (Fig. $3 B$, open circles) declined by $\sim 50 \%$ on cessation of stimulation. This drop indicates that $\left[\mathrm{Ca}^{2+}\right]_{\mathrm{i}}$ had been elevated during the depletion train. Elevations in $\left[\mathrm{Ca}^{2+}\right]_{\mathrm{i}}$ could also be evoked by short-stimulation trains after depletion stimulation (Fig. $3 C, D$ ). The average change in fluorescence increased linearly with stimulation frequency in the $10-40 \mathrm{~Hz}$ range (Fig. $3 D$, inset) $(n=3)$. This result is in good agreement with the single compartment model of Tank et al. (1995) in which $\mathrm{Ca}^{2+}$ reaches a plateau when entry and removal-sequestration are in balance. The boutons sectioned in Figure 2, $B$ and $C$, are the same as those from which the records shown in Figure $3 C$ were taken, 2 min before fixation.

\section{$\mathrm{Ca}^{2+}$ accumulation is reduced in shi boutons at $34^{\circ} \mathrm{C}$ before SV depletion}

OGB-1 fluorescence responses to trains of APs were compared between shi and wild-type $\mathrm{MN}$ terminals. At $22^{\circ} \mathrm{C}$, there was no difference in the response to stimulation between strains $(p \gg$ 0.05 ) (Fig. 4). In shi, the $\Delta F / F_{\mathrm{R}}$ response was reduced at $34^{\circ} \mathrm{C}$ relative to $22^{\circ} \mathrm{C}$. In $C S$, there was no decrease in the $\Delta F / F_{\mathrm{R}}$ response at $36^{\circ} \mathrm{C}$ relative to $22^{\circ} \mathrm{C}$ (data not plotted). However, in $O R$, from which $s h i$ was generated (Grigliatti et al., 1973), there was a reduction in $\Delta F / F_{\mathrm{R}}$ response between 22 and $34^{\circ} \mathrm{C}$. There was a similar reduction in the $\Delta F / F_{\mathrm{R}}$ response in shi between 22 and $34^{\circ} \mathrm{C}$; however, there was no difference between depleted and 
nondepleted shi $\mathrm{MN}$ terminals at $34^{\circ} \mathrm{C}$ (unpaired $t$ test; $p=0.63 ; n=6$ ). Thus, increasing the temperature results in a decrease in the $\Delta F / F_{\mathrm{R}}$ response independent of depletion stimulation. The decrease in fluorescence signal is not a result of depletion; as shown in Figure $2 A$, boutons heated without stimulation did not become depleted. There was no difference between the first measurement of the $\Delta F / F_{\mathrm{R}}$ response in $s h i$ at $22^{\circ} \mathrm{C}$ and the measurement from the same $\mathrm{MN}$ terminals, given time to recover at $22^{\circ} \mathrm{C}$, subsequent to depletion at $34^{\circ} \mathrm{C}$ (paired $t$ test; $p=$ $0.62 ; n=5)$.

\section{$\left[\mathrm{Ca}^{2+}\right]_{\mathrm{i}}$ kinetics during short high-}

frequency stimulation trains are unchanged in the absence of SVs

To examine the effect of SV depletion on $\left[\mathrm{Ca}^{2+}\right]_{\mathrm{i}}$ dynamics, we compared OGB-1 fluorescence with high temporal resolution in depleted and undepleted MN terminals. We collected these data by repeatedly scanning a single line through the center of type- $1 \mathrm{~b}$ boutons at a rate of $250 \mathrm{~Hz}$ (Macleod et al., 2002), while stimulating the nerve with a train of 80 pulses at $80 \mathrm{~Hz}$ (Fig. 5). In response to stimulation, there was an immediate elevation in OGB-1 fluorescence in nondepleted shiboutons at $34^{\circ} \mathrm{C}$, followed by a plateau for several hundred milliseconds and a rapid decay on cessation (Fig. $5 A$ ). After shi MN terminals had been depleted using the protocol described previously, OGB-1 fluorescence also increased rapidly with a rapid decay on cessation (Fig. $5 B)$. Depleted boutons are subjected to rigorous stimulation before gathering line-scan data, whereas nondepleted boutons are not. This treatment and the sustained $\mathrm{Ca}^{2+}$ load may compromise the ability of organelles (not SVs) to participate in normal $\mathrm{Ca}^{2+}$ handling during the short test trains that follow. We tested for the effect of the stimulation protocol alone, by subjecting $\mathrm{MN}$ terminals of $O R$ larvae (Fig. 5C) to the depletion protocol at $34^{\circ} \mathrm{C}$. OGB-1 fluorescence increased rapidly in response to $80 \mathrm{~Hz}$ stimulation as it did with nondepleted and depleted shi MN terminals and fell sharply with its cessation.

A plot of the average trace for each of the three treatments (Fig. 6A) indicates similarity in the $\mathrm{Ca}^{2+}$ dynamics between treatments. When the traces are normalized to the amplitude of the last $200 \mathrm{msec}$ of stimulation (Fig. $6 B$ ), the similarity in the dynamics is more obvious. Three parameters of the OGB- $1 \Delta F / F_{\mathrm{R}}$ response were measured for each treatment shown in Figure 5: maximum $\Delta F / F_{\mathrm{R}}$ amplitude (Fig. $6 C$ ), rise time (Fig. $6 D$ ), and time constant of decay after the 80th pulse (Fig. $6 E$ ). When these parameters are compared, it is clear that the trace for shi-depleted boutons is little different from the trace for

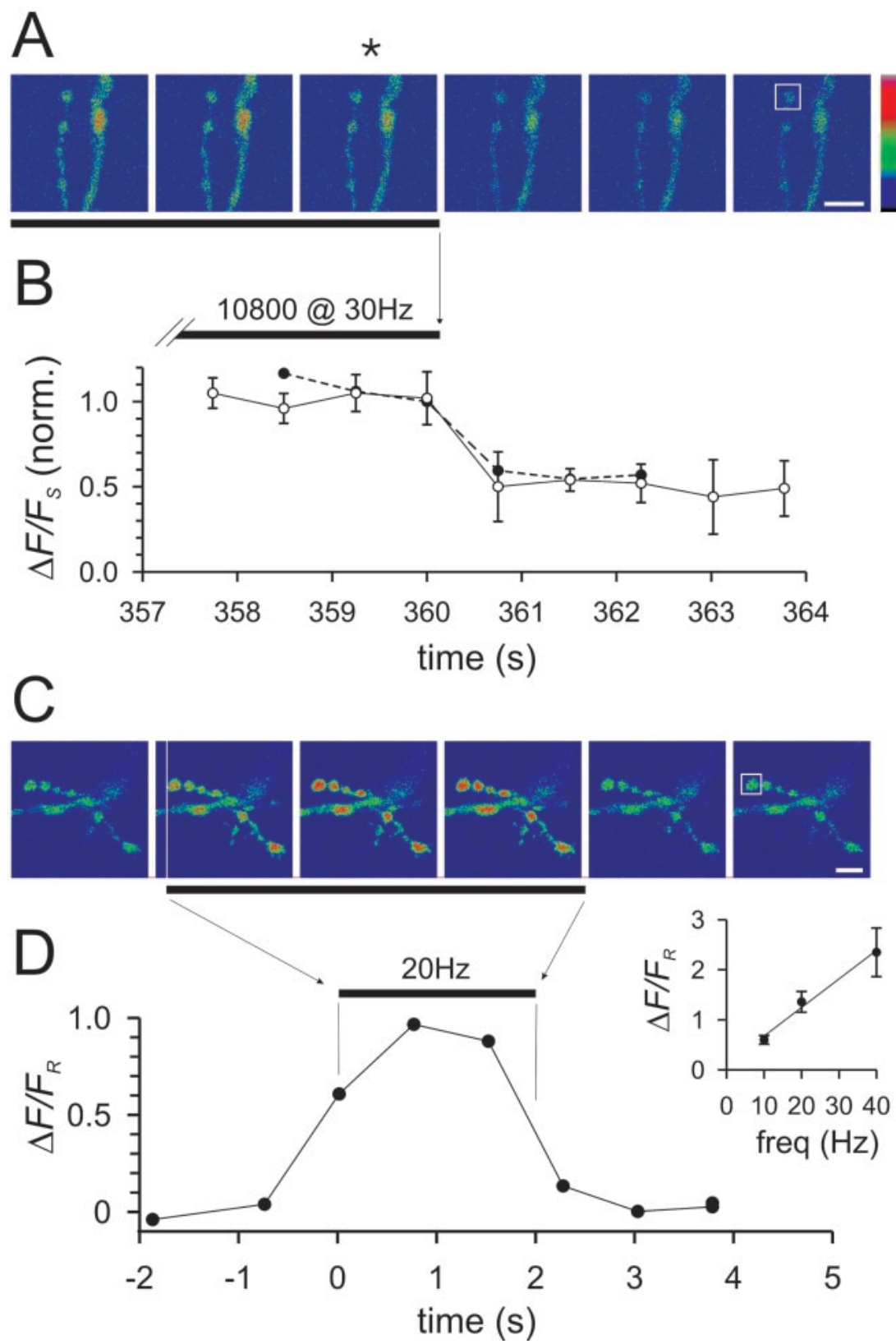

Figure 3. Nerve terminals of shi larvae, depleted of synaptic vesicles, exhibit robust $\mathrm{Ca}^{2+}$ signals at nonpermissive temperatures. $A$, Sequentially scanned images ( 680 msec interval) of OGB-1-loaded boutons in the cleft between muscles 6 and 7, at the end of a 6 min 30 $\mathrm{Hz}$ depletion train (horizontal blackbar) at $34^{\circ} \mathrm{C}$. The third image $\left(^{*}\right)$ is the last taken during the depletion train. After stimulation is stopped, the fluorescence rapidly declines. The bouton boxed in the sixth image was chosen for analysis over the image sequence. The fluorescence intensity of pixels $(0-255)$ is represented in the lookup table on the right. $B$, The change in fluorescence $(\Delta F)$ divided by the stimulated fluorescence level $\left(F_{S}\right)$ is plotted $\left(\Delta F / F_{S}\right)$ for the example shown in $A$ (filled circles) and for an average of five boutons in as many different larval preparations (open circles). $F_{S}$ is normalized to $1 . S D$ is indicated. $C$, Sequentially scanned images of 0GB-1-loaded boutons (muscles $6 / 7$ ), still at $34^{\circ} \mathrm{C}$, during a train of 40 pulses at $20 \mathrm{~Hz}$ delivered $2 \mathrm{~min}$ after the end of a $6 \mathrm{~min}$ depletion train. Note the white vertical scan line in the second panel marking the time of the first pulse in the 40 pulse train. Fluorescence increases rapidly as soon as stimulation is commenced. $D$, The change in fluorescence $(\Delta F)$ divided by the resting fluorescence level $\left(F_{R}\right)$ is plotted $\left(\Delta F / F_{R}\right)$ for the example shown (bouton within region of interest shown in sixth image of $C$ ). Average $\Delta F / F_{\mathrm{R}}$ is plotted against frequency of stimulation for depleted boutons in three other larval preparations under identical conditions (inset). SE is indicated. Scale bars: $A, C, 10 \mu \mathrm{m}$. All measurements were made in $\mathrm{HL} 6$ with $2 \mathrm{~mm}\left[\mathrm{Ca}^{2+}\right]_{0}$ and $4 \mathrm{~mm}\left[\mathrm{Mg}^{2+}\right]_{0}$.

nondepleted shi boutons at $34^{\circ} \mathrm{C}$, although both are similar to the traces for OR boutons subjected to the depletion protocol at $34^{\circ} \mathrm{C}$.

\section{Estimated $\left[\mathrm{Ca}^{2+}\right]_{\mathrm{i}}$ during stimulation}

We next asked whether volume-averaged $\left[\mathrm{Ca}^{2+}\right]_{\mathrm{i}}$ reaches a level comparable with that observed for maximal $\mathrm{Ca}^{2+}$ uptake by SVs 


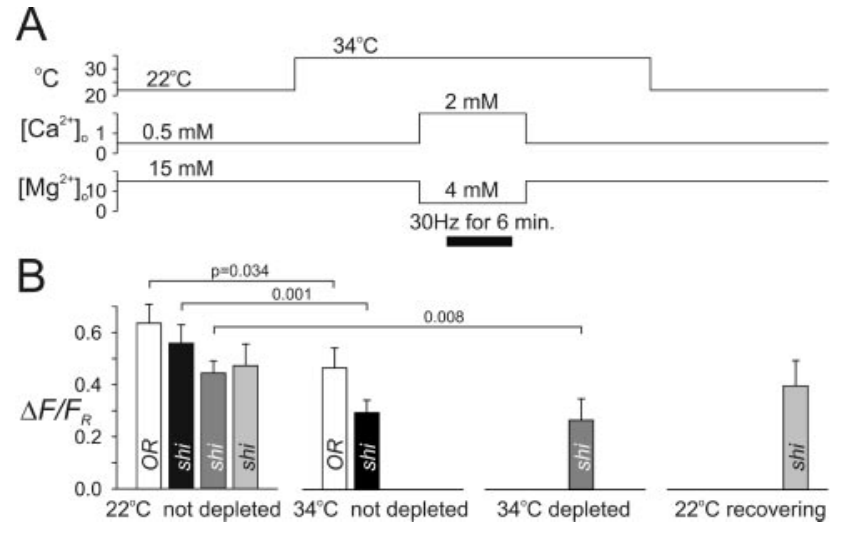

Figure 4. $\mathrm{Ca}^{2+}$ accumulation in shi nerve terminals during stimulation is reduced at $34^{\circ} \mathrm{C}$ before synaptic vesicle depletion. $A$, A representation of changes in temperature, $\left[\mathrm{Ca}^{2+}\right]_{0}$, and $\left[\mathrm{Mg}^{2+}\right]_{0}$ over time relative to the measurements reported in $B$ (not to scale). The location of the solid horizontal bar indicates the conditions under which a sustained train of stimulating pulses was applied to the segmental nerve to deplete nerve terminals of vesicles. $B$, Plots of the $0 G B-1$ $\Delta F / F_{R}$ response to trains of 40 pulses at $20 \mathrm{~Hz}$ under four different conditions (indicated below each abscissa), corresponding to the conditions indicated in $A$. Each of the bars in the first plot is paired (same boutons) with a bar in a plot to the right. $n>5$ for each of the pairs of bars. All significant differences ( $p<0.05 ; t$ test) between measurements are indicated with a joining line. All measurements were made in $\mathrm{HL} 6$ with $0.5 \mathrm{~mm}\left[\mathrm{Ca}^{2+}\right]_{0}$ and $15 \mathrm{~mm}\left[\mathrm{Mg}^{2+}\right]_{0}$.

in vitro. The $K_{\mathrm{m}}$ for ATP-dependent $\mathrm{Ca}^{2+}$ uptake by isolated cholinergic SVs has been estimated in the micromolar range (5 $\mu \mathrm{M}$, Israel et al., 1980; $50 \mu \mathrm{M}$, Michaelson et al., 1980; $52 \mu \mathrm{M}$, Rephaeli and Parsons, 1982). $\mathrm{Ca}^{2+}-\mathrm{H}^{+}$antiport activity in isolated SVs was optimally activated by $500 \mu \mathrm{M} \mathrm{Ca}{ }^{2+}$ (Gonçalves et al., 1998). To obtain an estimate of $\left[\mathrm{Ca}^{2+}\right]_{i}$ during trains of highfrequency activity in the $\mathrm{MN}$, such as those expected during locomotion, we used the ratiometric indicator fura (Fig. 7). The $\mathrm{MN}$ of fura-loaded terminals was stimulated at $80 \mathrm{~Hz}$ in the presence of either 0.5 or $2 \mathrm{mM}\left[\mathrm{Ca}^{2+}\right]_{\mathrm{o}}, 15 \mathrm{mM}\left[\mathrm{Mg}^{2+}\right]_{\mathrm{o}}$, and 7 $\mathrm{mM}$ [LGA]. Fura fluorescence in $\mathrm{OR}$ and shi MN terminals indicated a $\left[\mathrm{Ca}^{2+}\right]_{\mathrm{i}}$ resting level of $\sim 65 \mathrm{nM}$ and an elevated level of $\left[\mathrm{Ca}^{2+}\right]_{\mathrm{i}}$ during $80 \mathrm{~Hz}$ stimulation of $297 \pm 30 \mathrm{nM}$ in shi and $306 \pm 31 \mathrm{~nm}$ in $\mathrm{OR}$ at $0.5 \mathrm{~mm}\left[\mathrm{Ca}^{2+}\right]_{\mathrm{o}}$ (Fig. $\left.7 \mathrm{E}\right) .\left[\mathrm{Ca}^{2+}\right]_{\mathrm{i}}$ rose to only $389 \pm 34 \mathrm{nM}$ in $O R$ during $80 \mathrm{~Hz}$ stimulation in $2 \mathrm{~mm}$ $\left[\mathrm{Ca}^{2+}\right]_{\mathrm{o}}$ (Fig. $\left.7 F\right)$. Thus, volume-averaged $\left[\mathrm{Ca}^{2+}\right]_{\mathrm{i}}$ does not reach a level consistent with uptake observed in in vitro studies.

\section{$\left[\mathrm{Ca}^{2+}\right]_{\mathrm{i}}$ responses to single APs are unchanged in the absence} of SVs

The large amplitude and long time course of $\left[\mathrm{Ca}^{2+}\right]_{\mathrm{i}}$ changes in response to a high-frequency train of APs may overwhelm and mask more subtle differences in the influx and/or efflux of $\mathrm{Ca}^{2+}$ from the cytoplasm in the absence of SVs, which might indicate differences in $\mathrm{Ca}^{2+}$ influx and sequestration at the level of the microdomain. To investigate the possibility that VGCC opening probability and permeability is altered in the absence of SVs, or that less $\mathrm{Ca}^{2+}$ is intercepted and sequestered at the point of influx, we compared the amplitude and time course of volumeaveraged $\left[\mathrm{Ca}^{2+}\right]_{i}$ in response to single APs (Fig. 8). If SVs are required for VGCCs to open in response to an $\mathrm{AP}$, or to more generally relieve inhibition, we would expect a smaller $\mathrm{Ca}^{2+}$ response in the absence of SVs. Alternatively, if SVs play a role in sequestering $\mathrm{Ca}^{2+}$ on the periphery of the microdomains, their absence may result in a larger $\mathrm{Ca}^{2+}$ response.

The amplitude of the OGB- 1 response to a single AP in depleted shi MN terminals at $34^{\circ} \mathrm{C}$ was unchanged ( $p=0.34$; unpaired $t$ test) relative to the response in nondepleted $\mathrm{MN}$ termi-

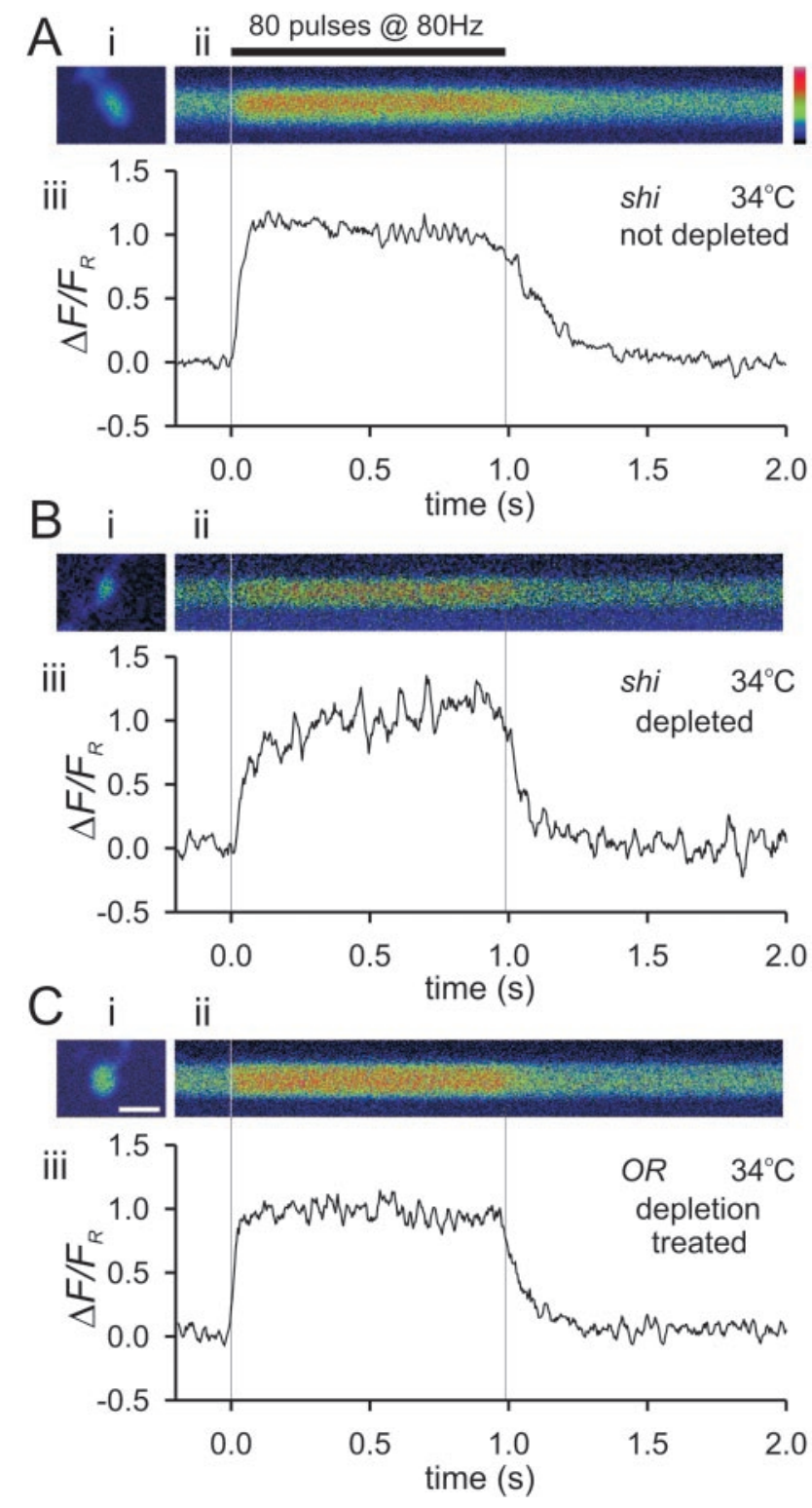

Figure 5. $\quad \mathrm{Ca}^{2+}$ transients during stimulus trains in synaptic vesicle-depleted nerve terminals do not differ greatly from controls. Ai, An image of fluorescence from a type-1b bouton filled with OGB-1. Aii, Sequential line scans through the center of the bouton. The white vertical scan line is coincident in time with the first pulse of an 80 pulse train delivered to the segment nerve of a shi larva at $80 \mathrm{~Hz}$, at a temperature of $34^{\circ} \mathrm{C}$. Lookup table to the right $(0-255)$. Aiii, $\Delta F / F_{\mathrm{R}}$ plotted for each vertical scan line in $A$. $B$, Stimulation-dependent changes in 0GB-1 fluorescence from a type- $1 \mathrm{~b}$ shibouton (Bi) depleted of vesicles at a temperature of $34^{\circ} \mathrm{C}$. Bii and Biii are as in Aii and Aiii. C, Stimulation-dependent changes in OGB-1 fluorescence from a type-1b OR bouton $(C i)$ at $34^{\circ} \mathrm{C}$, previously subjected to the standard depletion protocol. Cii and Ciii are as in Aii and Aiii. Maximum relative fluorescence changes are similar in all cases. All line scanning is performed at $4 \mathrm{msec}$ per line. Scale bar (in C): $A-C, 2 \mu \mathrm{m}$.

nals at $34^{\circ} \mathrm{C}$ (Fig. $8 \mathrm{~B}$ ). The time course of OGB-1 decay (extrusion-sequestration) after a single AP was also indistinguishable between treatments at $34^{\circ} \mathrm{C}(p=0.89$; unpaired $t$ test $)$ (Fig. 8C). The amplitude of the responses measured in shi at $34^{\circ} \mathrm{C}$ were not significantly lower that those at $22^{\circ} \mathrm{C}$ (Fig. $8 \mathrm{~B}$ ), but the time course of decay at $34^{\circ} \mathrm{C}$ was significantly faster than at $22^{\circ} \mathrm{C}$ for both depleted and nondepleted boutons (Fig. $8 \mathrm{C}$ ). Faster rates of $\mathrm{Ca}^{2+}$ extrusion in the depleted and nondepleted $\mathrm{MN}$ terminals at $34^{\circ} \mathrm{C}$, relative to $22^{\circ} \mathrm{C}$, can account for the reduced amplitudes of the OGB-1 response to stimulation trains (Fig. 4) at the higher temperature (Tank et al., 1995). 

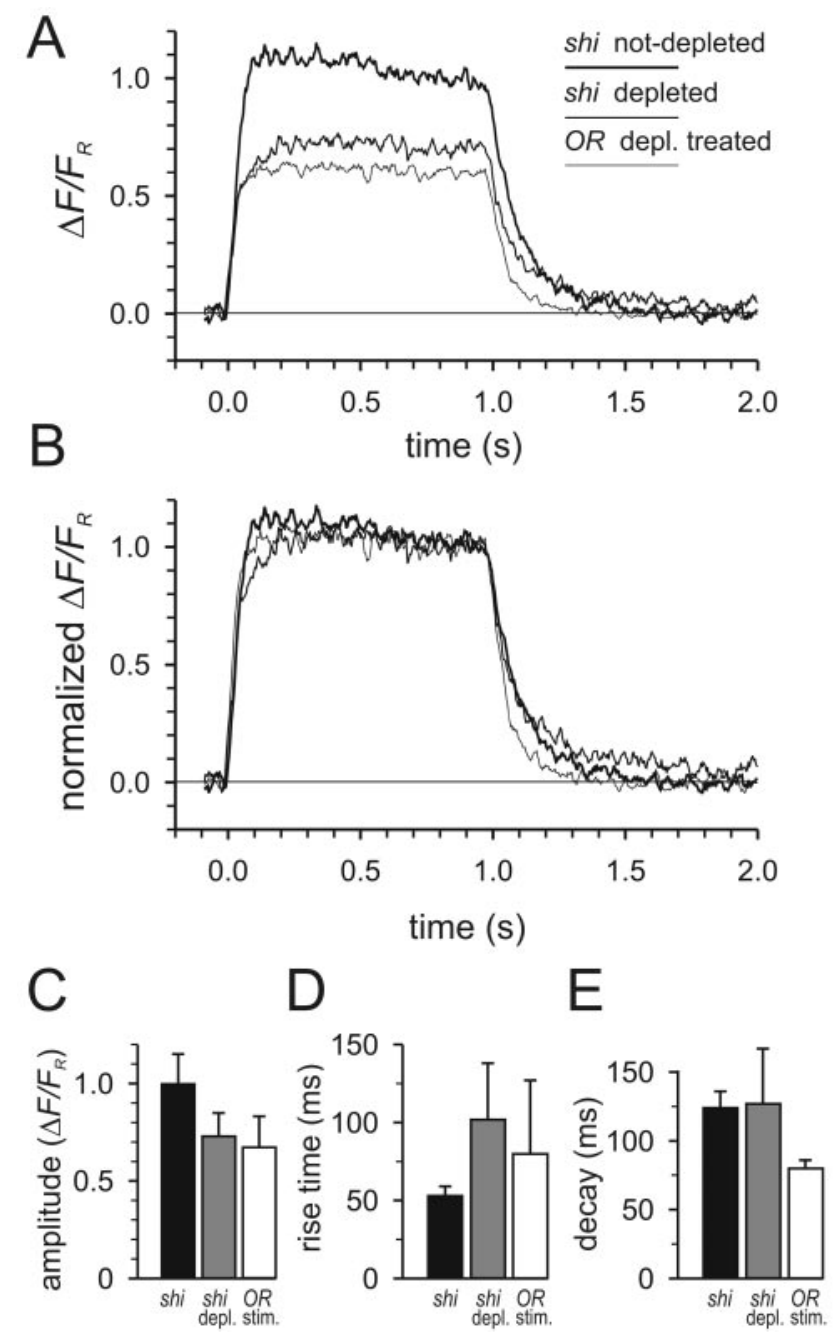

Figure 6. A comparison of the average time course of changes in $0 G B-1$ fluorescence, in response to short stimulation trains, between depleted shi nerve terminal boutons at $34^{\circ} \mathrm{C}$ and control preparations at $34^{\circ} \mathrm{C}$. $A$, The average plot of $\Delta F / F_{R}$ for line scans through shi nondepleted boutons ( $n=4)$, shi depleted boutons $(n=5)$, and $O R$ boutons subjected to previous depletion stimulation $(n=4)$, during stimulus trains of 80 pulses at $80 \mathrm{~Hz}$. $B$, The same traces as in $A$ normalized to the average amplitude of the $0 G B-1$ response over the last 200 msec of the stimulation train. $C-E$, Plots of the average bouton $0 G B-1$ fluorescence response for each treatment. $C$, Maximum $\Delta F / F_{R}$ amplitude; $D$, time taken to rise $20-80 \%$ of $\Delta F / F_{R}$ maximum; $E$, time constant of decay after the 80th pulse.

\section{Discussion}

The present study used an endocytosis mutation of Drosophila to allow a comparison of AP-induced $\mathrm{Ca}^{2+}$ signals in nerve terminals containing SVs and those depleted of SVs. Calcium imaging data collected under the two contrasting conditions provided a test of the hypothesis that SVs directly regulate $\mathrm{Ca}^{2+}$ entry through VGCCs. The same data also allowed a test of the hypothesis that SVs contribute to neuronal $\mathrm{Ca}^{2+}$ homeostasis through rapid sequestration of $\mathrm{Ca}^{2+}$ during and shortly after APs.

\section{$\mathrm{Ca}^{2+}$ influx during APs does not require SVs}

In shi larval preparations maintained at $34^{\circ} \mathrm{C}$, we observed an elevation in the level of fluorescence from the intracellular $\mathrm{Ca}^{2+}$ indicator in response to stimulation $(30 \mathrm{~Hz})$ of the segmental nerve. This fluorescence elevation was sustained for $6 \mathrm{~min}$ and fell immediately on cessation of stimulation (Fig. $3 A, B$ ). Subsequent examination of boutons subjected to this stimulation confirmed that all SVs were gone (Fig. 2). Because the fluorescence response was observed during the entire stimulus train and SVs were eliminated, we conclude that $\mathrm{SV}$ depletion $\operatorname{did}$ not affect $\mathrm{Ca}^{2+}$ entry and also that AP failure did not affect our SV depletion protocol. Subsequent short trains of stimuli at $34^{\circ} \mathrm{C}$ evoked fluorescence changes (Fig. 3C,D) indistinguishable in amplitude from those evoked before depletion at $34^{\circ} \mathrm{C}$ (Fig. 4). An analysis of fluorescence responses to single APs at $34^{\circ} \mathrm{C}$, subsequent to depletion, showed no difference in the amplitude and time course of the $\mathrm{Ca}^{2+}$ signal relative to those before depletion at $34^{\circ} \mathrm{C}$ (Fig. 8). We conclude that regulation of VGCCs does not require SVs to bring presynaptic proteins into interaction with VGCC binding domains. These data do not preclude the possibility that either synaptotagmin and/or cysteine string proteins are regulators of VGCC activity and depolarization-invoked $\mathrm{Ca}^{2+}$ entry (Chen et al., 2002); however, if so, they are not required to be brought into organized interaction with the VGCC via an SV.

The data presented here are in contrast to another study that examined the Drosophila shi mutant (Umbach et al., 1998). Umbach and colleagues loaded the permeant $\mathrm{AM}$ form of the $\mathrm{Ca}^{2+}$ indicator Calcium Crimson into shi larval MN terminals. After incubating the preparation at $32^{\circ} \mathrm{C}$ for $10 \mathrm{~min}$, the nerve was stimulated $(10 \mathrm{~Hz}$ for 1-2 min) until muscle contraction ceased and was allowed to rest for an additional $5 \mathrm{~min}$ at $32^{\circ} \mathrm{C}$. Subsequent stimulation at $10 \mathrm{~Hz}$ at $32^{\circ} \mathrm{C}$ caused no discernable increase in Calcium Crimson fluorescence. Although we note that $10 \mathrm{~Hz}$ stimulation for up to $2 \mathrm{~min}$ (1200 pulses) is unlikely to deplete the MN terminals of SVs (Delgado et al., 2000) and that muscle contraction ceases well in advance of SV depletion, we are unable to reconcile these data with our own. A possibility is that the loading procedure, requiring up to $3 \mathrm{hr}$ incubation in a conventional saline solution (Jan and Jan, 1976) followed by preparation heating, may result in AP failure during repeated stimulation at $32^{\circ} \mathrm{C}$ in temperature-sensitive mutants such as shi.

\section{A role for SVs in rapid presynaptic sequestration of $\mathrm{Ca}^{2+}$ could not be detected}

Just as the amplitude of the $\mathrm{Ca}^{2+}$ response to stimulation in lizard MN terminals increases when sequestration of $\mathrm{Ca}^{2+}$ by mitochondria is blocked (David and Barrett, 2000) we predicted an increase in the $\mathrm{Ca}^{2+}$ response in Drosophila MN terminals depleted of SVs. However, in response to $80 \mathrm{~Hz}$ stimulation, MN terminals depleted of SVs showed no change in the rate of rise in $\left[\mathrm{Ca}^{2+}\right]_{\mathrm{i}}$, the amplitude of the plateau achieved after $1 \mathrm{sec}$, or the subsequent decay in $\left[\mathrm{Ca}^{2+}\right]_{\mathrm{i}}$ relative to nondepleted $\mathrm{MN}$ terminal boutons (Fig. 6). In an attempt to detect subtle effects of $\mathrm{Ca}^{2+}$ sequestration by $S V s$, we examined $\left[\mathrm{Ca}^{2+}\right]_{\mathrm{i}}$ responses to single APs in depleted boutons (Fig. 8). Numerous electron microscopy ultrastructural studies have shown that SVs densely crowd the active zone at the Drosophila NMJ, in which they present a significant surface area to intercept the incoming $\mathrm{Ca}^{2+}$ before it can diffuse throughout the cytosol (Atwood et al., 1993). In addition, some SVs are "docked" at the active zone beside PM-containing VGCCs; here, $\left[\mathrm{Ca}^{2+}\right]$ in microdomains $\left(\left[\mathrm{Ca}^{2+}\right]_{\mathrm{m}}\right)$, within $50 \mathrm{~nm}$ of the VGCC mouth, has been estimated to exceed several $100 \mu \mathrm{M}$ [Llinas et al., $1992(200-300 \mu \mathrm{M})$ ] [but see Meinrenken et al., $2003(10-30 \mu \mathrm{M})$ ]. We predicted that, if SVs are no longer present to intercept a significant portion of $\mathrm{Ca}^{2+}$ influx through VGCCs, there would be a greater, or more rapid, increase in $\left[\mathrm{Ca}^{2+}\right]_{\mathrm{i}}$ in response to a single AP. No such changes were observed, nor was there a change in time course of the decay of the $\mathrm{Ca}^{2+}$ signal.

In the analysis above, assumptions are made that the volumeaveraged $\mathrm{Ca}^{2+}$ reported by the $\mathrm{Ca}^{2+}$ indicator reflects changes in sequestration by SVs at the level of the active zone and that the $\mathrm{Ca}^{2+}$ 

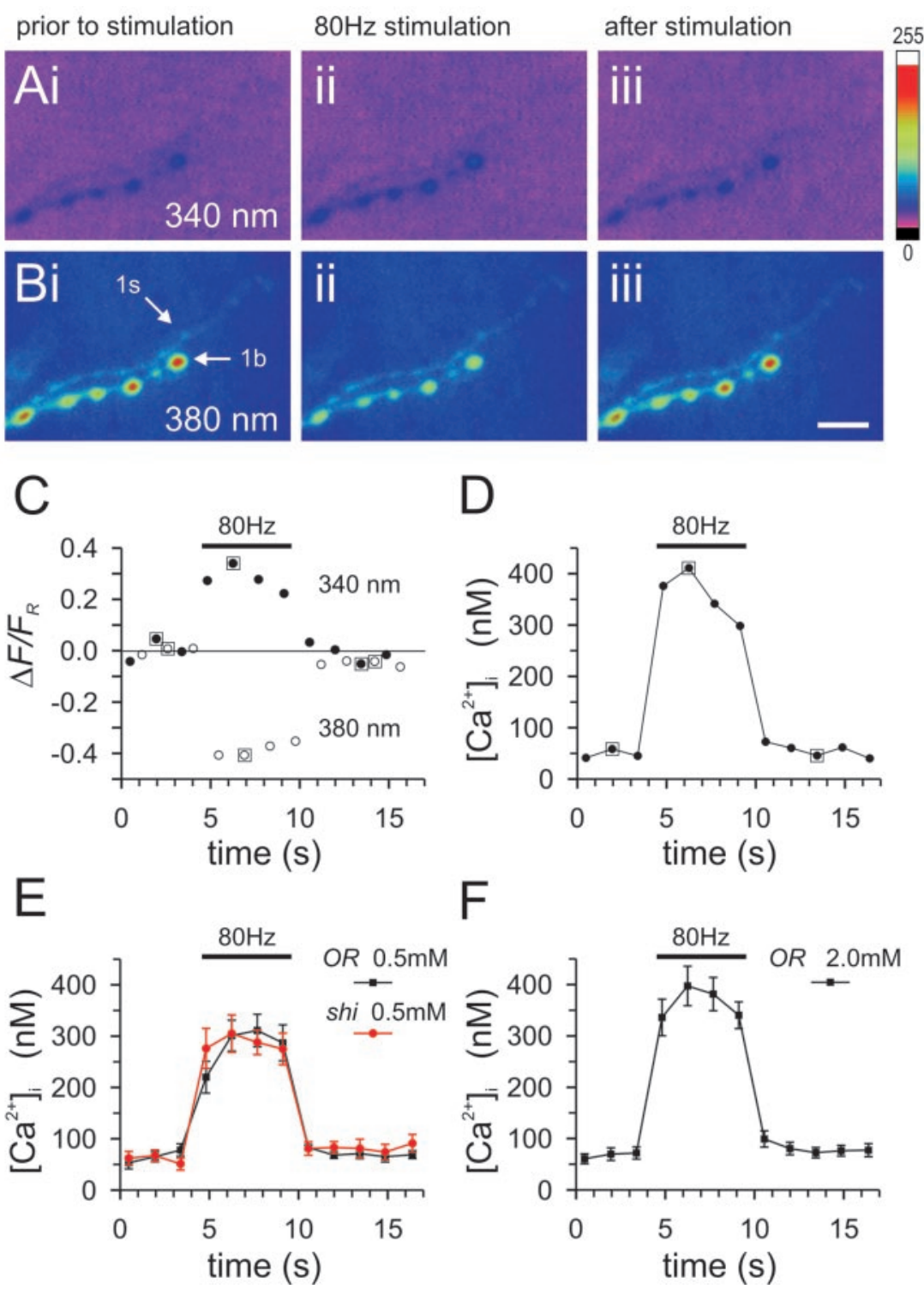

Figure 7. The concentration of free $\mathrm{Ca}^{2+}$ in the nerve terminals remains submicromolar during high-frequency stimulation at $22^{\circ} \mathrm{C}$. A, Images of fura-dextran-filled type- $1 \mathrm{~b}$ boutons acquired through a $530 \pm 35 \mathrm{~nm}$ bandpass filter, while they were exposed to excitation illumination through a $340 \pm 5 \mathrm{~nm}$ filter. Ai, Before stimulation; Aii, during stimulation at $80 \mathrm{~Hz}$; Aiii, after stimulation. $\left[\mathrm{Ca}^{2+}\right]_{0}$ of $2 \mathrm{~mm}$. $B$, Images of the same boutons as in $A$, acquired through a $530 \pm 35 \mathrm{~nm}$ filter, while they were illuminated through a $380 \pm 5 \mathrm{~nm}$ filter. Bi-Biii as in $A i-A i i i$. Scale bar: $A, B, 10 \mu \mathrm{m}$. Lookup table on the right-hand side. C, A plot of $\Delta F / F_{\mathrm{R}}$ for the most distal type-1b bouton, before, during, and after a train of 400 pulses at $80 \mathrm{~Hz}$ (filled circles, $340 \mathrm{~nm}$ excitation; open circles, $380 \mathrm{~nm}$ excitation). Image pairs in $A$ and $B$ correspond to boxed plotted values in $(: i, 2 \mathrm{nd} ; i i, 5$ th; $i i i, 10$ th. $D$, A plot of $\left[\mathrm{Ca}^{2+}\right]_{\mathrm{i}}$ against time, for each image pair, estimated from the ratio of the fluorescence of the bouton in $A$ to that in $B$. $E$, A plot of average $\left[\mathrm{Ca}^{2+}\right]_{\mathrm{i}}$ against time for $O R($ black; $n=6)$ and shi $(\mathrm{red} ; n=7)$ type- 1 b boutons in $0.5 \mathrm{~mm}\left[\mathrm{Ca}^{2+}\right]_{0} . F, A$ plot of average $\left[\mathrm{Ca}^{2+}\right]_{\mathrm{i}}$ against time for $O R$ type-1b boutons $(n=8)$ in $2 \mathrm{~mm}\left[\mathrm{Ca}^{2+}\right]_{0}$. SE is indicated.

indicator is capable of revealing reductions in the time course of decay below $38 \mathrm{msec}$. Regarding the first assumption, numerical models indicate that all changes in microdomain $\mathrm{Ca}^{2+}$ will be proportionally reflected in the volume-averaged $\left[\mathrm{Ca}^{2+}\right]_{\mathrm{i}}$ (Bennett et al., 2000 ). In the second major assumption, although OGB-1 has a high affinity for $\mathrm{Ca}^{2+}$, it is capable of reporting a rapid decay in cytosolic $\mathrm{Ca}^{2+}$. Decay time constants of $\sim 30 \mathrm{msec}$ have been reported using OGB-1 at a concentration of $20 \mu \mathrm{M}$ in dendrite spines of small volume (Sabatini et al., 2002). We have no estimate of cytosolic OGB-1 concentration in this study and cannot conclude that the absence of a difference in the time course of the $\mathrm{Ca}^{2+}$ signal, in response to single APs between depleted and undepleted boutons, constitutes a legitimate test of the sequestration role of vesicles at the microdomain. However, because the amplitude is unchanged between the depleted and undepleted preparations, we conclude that SVs are unlikely to have a role in $\mathrm{Ca}^{2+}$ sequestration at the level of the microdomain and are thus unlikely to affect transmitter release by this mechanism. Furthermore, it is unlikely that $\mathrm{Ca}^{2+}$ uptake by SVs alters the volume-averaged $\left[\mathrm{Ca}^{2+}\right]_{\mathrm{i}}$ signal, which is important for signaling pathways such as CaMKII activation on SVs distal to the active zone.

\section{Transmembrane ion gradients reverse across the SV membrane when SVs fuse with the plasma membrane}

When SVs fuse with the PM, the SV membrane becomes continuous with the PM, with the lumenal side of the SV membrane now facing the extracellular solution. With prolonged stimulation of shibire boutons at $34^{\circ} \mathrm{C}$, all of the SV membrane accumulates on the PM. The entire expanded membrane surface maintains contact with the extracellular solution until the temperature is reduced to permissive levels (Poskanzer et al., 2003). For this reason, the cytosol of a depleted bouton maintains contact with the same area of SV membrane as in a nondepleted bouton. In addition, the $\mathrm{Ca}^{2+}$-permeable macromolecules, originally located in the SV membranes, maintain their orientation relative to the cytosol. These $\mathrm{Ca}^{2+}$ permeable macromolecules, be they passive transporters or pumps, will not manifest the same activity in the PM as they did when located in discrete SVs. The $\mathrm{H}^{+}$gradient is neutralized, and the $\mathrm{Ca}^{2+}$ gradient changes by as much as $4 \log$ units. The trans-SV membrane proton and $\mathrm{Ca}^{2+}$ gradients, as well as the electrical potential, now favor movement of $\mathrm{Ca}^{2+}$ from the original lumenal side of the SV membrane (now facing the extracellular medium) into the cytosol. This would reverse the hypothetical $\mathrm{Ca}^{2+}$ transporting activity of SVs in their role as organelles capable of $\mathrm{Ca}^{2+}$ sequestration from the cytosol. Thus, depletion of SVs would be expected to eliminate any $\mathrm{Ca}^{2+}$ sequestration that SVs normally effect at nondepleted synapses. Our measurements indicate that SVs normally have a negligible role in $\mathrm{Ca}^{2+}$ sequestration.

\section{$\mathrm{Ca}^{2+}$ uptake by SVs may be endocytotic}

If $S V s$ are not substantially involved in regulating $\left[\mathrm{Ca}^{2+}\right]_{\mathrm{i}}$ in $\mathrm{MN}$ terminals during sustained stimulation, why is $\mathrm{Ca}^{2+}$ found concentrated in SVs in various nerve cells? One possibility is that $\mathrm{Ca}^{2+}$ in SVs is simply a consequence of endocytosis of an SV open to the extracellular milieu from which $\mathrm{Ca}^{2+}$ cannot be excluded. During endocytosis, synaptic vesicles acquire the $\mathrm{pH}$ of the external solution (Gandhi and Stevens, 2003), as well as compounds 

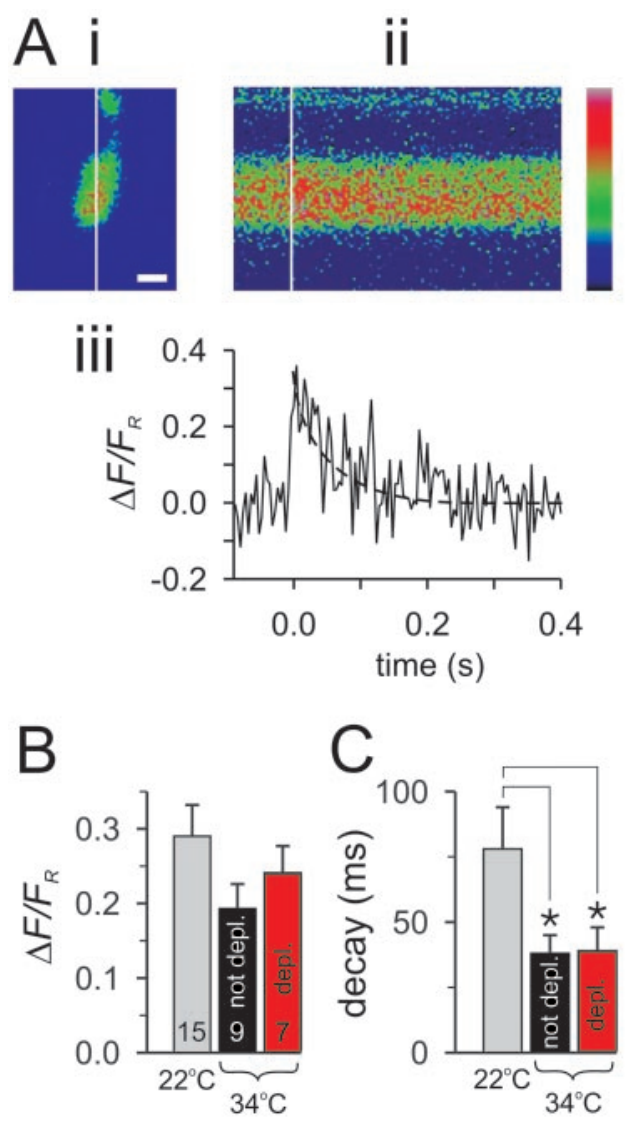

Figure 8. $\quad \mathrm{Ca}^{2+}$ transients during single stimulus pulses in synaptic vesicle-depleted terminal boutons are indistinguishable from those in nondepleted boutons at $34^{\circ} \mathrm{C}$. Ai, An image of fluorescence from a type-1b bouton filled with 0GB-1.Scale bar, $2 \mu \mathrm{m}$. Aii, Sequential line scans through the center of the bouton. The white vertical scan line is coincident in time with a single pulse delivered to the segmental nerve of a shi larva at a temperature of $22^{\circ} \mathrm{C}$. Lookup table to the right $(0-255)$. Aiii, $\Delta F / F_{\mathrm{R}}$ plotted for each vertical scan line in Aii. $B$, A plot of the average $\Delta F / F_{R}$ amplitude in response to a single pulse in shi boutons at $22^{\circ} \mathrm{C}$ and at $34^{\circ} \mathrm{C}$ (depleted and undepleted boutons); the number of preparations ( $n$ ) for each condition is indicated on each bar. C, A plot of the average decay time constant in response to a single pulse in shi boutons; number of preparations as in $B\left({ }^{*} p<0.05\right.$; unpaired $t$ tests). There were no differences in $\mathrm{Ca}^{2+}$ signals between depleted and undepleted boutons at $34^{\circ} \mathrm{C}$.

that are in the extracellular milieu [HRP, Jones et al., 1977, Meshul and Pappas, 1984, Parducz, 1986; fluorescein-conjugated dextran, Bonzelius and Zimmermann, 1990, Masur et al., 1990; the buffer Tris (during kiss-and-run events), Gandhi and Stevens, 2003], whereas $\mathrm{Ca}^{2+}$ is taken up through the exocytotic pore of mast cell granules (Raison et al., 1999). If $\mathrm{Ca}^{2+}$ is taken up into SVs during endocytosis, we would expect SVs in recently stimulated tissues to have higher concentrations of $\mathrm{Ca}^{2+}$ as is found in Torpedo (Parducz and Dunant, 1993; Parducz et al., 1994) and the rat (Parducz et al., 1987). We would also anticipate the number of SVs containing $\mathrm{Ca}^{2+}$ to increase over a time course similar to that of compensatory endocytosis rather than that of elevated $\left[\mathrm{Ca}^{2+}\right]_{\mathrm{i}}$ evoked by stimulation, and this also is observed (Parducz and Dunant, 1993; Parducz et al., 1987, 1994). These data suggest that $\mathrm{Ca}^{2+}$ is concentrated in SVs as a result of endocytosis from the extracellular solution rather than by a process of $\mathrm{Ca}^{2+}$ uptake from the cytosol.

If an $\mathrm{SV}$ is endocytosed into the cytosol with a $\mathrm{Ca}^{2+}$ gradient of over 4 log units across its membrane, implications are evident for both the loading of transmitters into SVs and the facilitation of transmitter release. $\mathrm{Ca}^{2+}$ would exchange for protons via an- tiporters in the SV membrane, generating a proton motive force for "first stage" loading of transmitters, whereas the $\mathrm{Ca}^{2+}$ pump may run in reverse. Data supporting such an exchange of protons and $\mathrm{Ca}^{2+}$ was reported from cultured fibroblast cells, in which the time course of $\mathrm{Ca}^{2+}$ loss from endosomes matched the time course of acidification (Gerasimenko et al., 1998). Furthermore, acidification of endosomes was blocked by bafilomycin, a specific blocker of the vacuolar proton ATPase, which in turn blocked the leak of $\mathrm{Ca}^{2+}$ from the endosomes.

A slow leak of $\mathrm{Ca}^{2+}$ from a freshly endocytosed SV might contribute to the local $\left[\mathrm{Ca}^{2+}\right]_{\mathrm{i}}$ and thus might contribute to short-term facilitation of transmitter release. The effect of the leak on volume-averaged $\left[\mathrm{Ca}^{2+}\right]_{\mathrm{i}}$ may be difficult to detect because of its limited spatial extent (close to the PM, across which it is immediately extruded) and low flux rate. Indeed, if 25 vesicles, each of inner diameter $21 \mathrm{~nm}$ (Karunanithi et al., 2002) and containing $2 \mathrm{mM} \mathrm{Ca}^{2+}$, were endocytosed into a bouton $3 \mu \mathrm{M}$ in diameter, where they instantaneously lost all of their $\mathrm{Ca}^{2+}$ to the cytosol, it could raise $\left[\mathrm{Ca}^{2+}\right]_{\mathrm{i}}$ no more than $20 \mathrm{nM}$. Considering that acidification of the SVs (and presumably loss of $\mathrm{Ca}^{2+}$ ) has a time course of $\sim 430 \mathrm{msec}$ (Gandhi and Stevens, 2003), the effect on volume-averaged $\left[\mathrm{Ca}^{2+}\right]_{\mathrm{i}}$ would be undetectable.

\section{$\mathrm{SV} \mathrm{Ca}^{2+}$ transporters: physiological implications}

The maximum volume-averaged $\left[\mathrm{Ca}^{2+}\right]_{\mathrm{i}}$ attained in the $\mathrm{MN}$ terminals during high-frequency stimulation at $22^{\circ} \mathrm{C}$ was $\sim 0.4 \mu \mathrm{M}$. This value is in general agreement with $\left[\mathrm{Ca}^{2+}\right]_{\mathrm{i}}$ reported in other $\mathrm{MN}$ terminals during stimulation $(\sim 1 \mu \mathrm{M}$; crayfish, Tank et al., 1995, Msghina et al., 1999; frog, Suzuki et al., 2000; mouse, David and Barrett, 2000) but is well below estimates for microdomain $\left[\mathrm{Ca}^{2+}\right]$ of 10-30 $\mu \mathrm{M}$ (Meinrenken et al., 2003). However, both values contrast sharply with the optimal $\mathrm{Ca}^{2+}$ concentration $(500 \mu \mathrm{M})$ for inducing $\mathrm{H}^{+}$release from $\mathrm{SV}$ s isolated from sheep brain (Gonçalves et al., 1998). If $\mathrm{Ca}^{2+}$ at a concentration comparable with extracellular levels $(\sim 2 \mathrm{mM})$ is trapped inside newly endocytosed SVs, then the $\mathrm{Ca}^{2+}$ gradient across the SV membrane in vivo $\left(10^{-3}: 10^{-7}\right.$, intra$\mathrm{SV} /$ cytosolic) contrasts sharply with the gradient manipulated in vitro $\left(10^{-9}: 10^{-3}\right)$ in which $\mathrm{Ca}^{2+}$ uptake was observed in isolated SVs (Gonçalves et al., 1998). Similarly, the proton gradient across the SV membrane in vivo $\left(10^{-5.7}: 10^{-7}\right.$; intra-SV, Miesenböck et al., 1998; cytosolic, Berridge et al., 2003) is unlikely, by exchange activity alone, to result in $\mathrm{Ca}^{2+}$ uptake, yet the levels manipulated in vitro are favorable for $\mathrm{Ca}^{2+}$ uptake $\left(10^{-8}: 10^{-7}\right)$. Thus, it is reasonable to expect that, in vivo, the SV membrane $\mathrm{Ca}^{2+}-\mathrm{H}^{+}$exchanger would be important for the concentration of $\mathrm{H}^{+}$in the vesicles, particularly in the presence of a high intra-lumenal $\left[\mathrm{Ca}^{2+}\right]$, and not relevant to $\mathrm{Ca}^{2+}$ sequestration or intraterminal $\left[\mathrm{Ca}^{2+}\right]$ homeostasis during or after APs. The $\mathrm{Ca}^{2+}$ affinity of the SV membrane $\mathrm{Ca}^{2+}$ pump $(\sim 5-50 \mu \mathrm{M})$ falls well within the range of microdomain $\left[\mathrm{Ca}^{2+}\right]$ estimates, but our measurements could detect no influence on volume-averaged $\left[\mathrm{Ca}^{2+}\right]$.

\section{References}

Adler EM, Augustine GJ, Duffy SN, Charlton MP (1991) Alien intracellular calcium chelators attenuate neurotransmitter release at the squid giant synapse. J Neurosci 11:1496-1507.

Atwood HL, Govind CK, Wu C-F (1993) Differential ultrastructure of synaptic terminals on ventral longitudinal abdominal muscles in Drosophila larvae. J Neurobiol 24:1008-1024.

Barclay JW, Atwood HL, Robertson RM (2002) Impairment of central pattern generation in Drosophila cysteine string protein mutants. J Comp Physiol 88:71-78.

Bennett MR, Farnell L, Gibson WG (2000) The probability of quantal secretion near a single calcium channel of an active zone. Biophys J 78:2201-2221. 
Berridge MJ, Bootman MD, Roderick HL (2003) Calcium signalling: dynamics, homeostasis and remodelling. Nat Rev Mol Cell Biol 4:517-529.

Bonzelius F, Zimmermann H (1990) Recycled synaptic vesicles contain vesicle but not plasma membrane marker, newly synthesized acetylcholine, and a sample of extracellular medium. J Neurochem 55:1266-1273.

Cattaert D, Birman S (2001) Blockade of the central generator of locomotor rhythm by noncompetitive NMDA receptor antagonists in Drosophila larvae. J Neurobiol 48:58-73.

Catterall WA (2000) Structure and regulation of voltage-gated $\mathrm{Ca}^{2+}$ channels. Annu Rev Cell Dev Biol 16:521-555.

Chen MS, Obar RA, Schroeder CC, Austin TW, Poodry DA, Wadsworth SC, Vallee RB (1991) Multiple forms of dynamin are encoded by shibire, a Drosophila gene involved in endocytosis. Nature 351:583-586.

Chen S, Zheng X, Schulze KL, Morris T, Bellen H, Stanley EF (2002) Enhancement of presynaptic calcium current by cysteine string protein. J Physiol (Lond) 538 2:383-389.

David G, Barrett EF (2000) Stimulation-evoked increases in cytosolic $\left[\mathrm{Ca}^{2+}\right]$ in mouse motor nerve terminals are limited by mitochondrial uptake and are temperature-dependent. J Neurosci 20:7290-7296.

Delgado R, Maureira C, Oliva C, Kidokoro Y, Labarca P (2000) Size of vesicle pools, rates of mobilization, and recycling at neuromuscular synapses of a Drosophila mutant, shibire. Neuron 28:941-953.

Gandhi SP, Stevens CF (2003) Three modes of synaptic vesicular recycling revealed by single-vesicle imaging. Nature 423:607-613.

Gerasimenko JV, Tepikin AV, Petersen OH, Gerasimenko OV (1998) Calcium uptake via endocytosis with rapid release from acidifying endosomes. Curr Biol 3:1335-1338.

Gonçalves PP, Meireles SM, Gravato C, Vale MGP (1998) $\mathrm{Ca}^{2+}-\mathrm{H}^{+}$antiport activity in synaptic vesicles isolated from sheep brain cortex. Neurosci Lett 247:87-90.

Grigliatti TA, Hall L, Rosenbluth R, Suzuki DT (1973) Temperaturesensitive mutations in Drosophila melanogaster. XIV. A selection of immobile adults. Mol Gen Genet 120:104-114.

Grynkiewicz G, Poenie M, Tsien RY (1985) A new generation of $\mathrm{Ca}^{2+}$ indicators with greatly improved fluorescence properties. J Biol Chem 260:3440-3450.

Harlow ML, Ress D, Stoschek A, Marshall RM, McMahan UJ (2001) The architecture of active zone material at the frog's neuromuscular junction. Nature 409:479-484.

Israel M, Manaranche R, Marsal J, Meunier FM, Morel N, Frachon P, Lesbats B (1980) Calcium uptake by cholinergic synaptic vesicles. J Physiol (Paris) 76:479-485.

Jan LY, Jan YN (1976) Properties of the larval neuromuscular junction in Drosophila melanogaster. J Physiol (Lond) 262:189-214.

Jones DG, Cameron PU, Ellison LT (1977) The uptake of horseradish peroxidase by cortical synapses in rat brain. An in vivo study. Cell Tissue Res 178:355-373.

Karunanithi S, Marin L, Wong K, Atwood HL (2002) Quantal size and variation determined by vesicle size in normal and mutant Drosophila glutamatergic synapses. J Neurosci 22:10267-10276.

Kawasaki F, Hazen M, Ordway RW (2000) Fast synaptic fatigue in shibire mutants reveals a rapid requirement for dynamin in synaptic vesicle membrane trafficking. Nat Neurosci 3:859-860.

Koenig JH, Ikeda K (1983) Evidence for a presynaptic blockage of transmission in a temperature-sensitive mutant of Drosophila. J Neurobiol 14:411-419.

Koenig JH, Ikeda K (1989) Disappearance and reformation of synaptic vesicle membrane upon transmitter release observed under reversible blockage of membrane retrieval. J Neurosci 9:3844-3860.

Koenig JH, Ikeda K (1999) Contribution of active zone subpopulation of vesicles to evoked and spontaneous release. J Neurophysiol 81:1495-1505.

Koenig JH, Yamaoka K, Ikeda K (1998) Omega images at the active zone may be endocytotic rather than exocytotic: implications for the vesicle hypothesis of transmitter release. Proc Natl Acad Sci USA 95:12677-12682.

Kosaka T, Ikeda K (1983) Possible temperature-dependent blockage of synaptic vesicle recycling induced by a single gene mutation in Drosophila. J Neurobiol 14:207-225.

Kuromi H, Kidokoro Y (2000) Tetanic stimulation recruits vesicles from reserve pool via a cAMP-mediated process in Drosophila synapses. Neuron 27:133-143.

Llinas R, Sugimori M, Silver RB (1992) Microdomains of high calcium concentrations in a presynaptic terminal. Science 256:677-679.

Macleod GT, Hegström-Wojtowicz M, Charlton MP, Atwood HL (2002)
Fast calcium signals in Drosophila motor neuron terminals. J Neurophysiol 88:2659-2663.

Masur SK, Kim Y-T, Wu C-F (1990) Reversible inhibition of endocytosis in cultured neurons from the Drosophila temperature-sensitive mutant shibire $^{\text {ts1 }}$. J Neurogenet 6:191-206.

Meinrenken CJ, Borst JG, Sakmann B (2003) Local routes revisited: the space and time dependence of the $\mathrm{Ca}^{2+}$ signal for phasic transmitter release at the rat calyx of Held. J Physiol (Lond) 547:665-689.

Meshul CK, Pappas GD (1984) The relationship of pinocytosis and synaptic vesicles at the frog neuromuscular junction. Brain Res 290:1-18.

Michaelson DM, Ophir I, Angel I (1980) ATP-stimulated $\mathrm{Ca}^{2+}$ transport into cholinergic Torpedo synaptic vesicles. J Neurochem 35:116-124.

Miesenböck G, De Angelis DA, Rothman JE (1998) Visualizing secretion and synaptic transmission with $\mathrm{pH}$-sensitive green fluorescent proteins. Nature 394:192-195.

Mizuhira V, Hasegawa H (1997) Microwave fixation and localization of calcium in synaptic terminals using $\mathrm{x}$-ray microanalysis and electron energy loss spectroscopy imaging. Brain Res Bull 43:53-58.

Msghina M, Millar AG, Charlton MP, Govind CK, Atwood HL (1999) Calcium entry related to active zones and differences in transmitter release at phasic and tonic synapses. J Neurosci 19:8419-8434.

Parducz A (1986) Horseradish peroxidase uptake of the synaptic vesicles in the superior cervical ganglion of the cat. Brain Res 362:375-378.

Parducz A, Dunant Y (1993) Transient increase of calcium in synaptic vesicles after stimulation. Neuroscience 52:27-33.

Parducz A, Toldi J, Joo F, Siklos L, Wolff JR (1987) Transient increase in calcium in pre- and post synaptic organelles of rat superior cervical ganglion after tetanizing stimulation. Neuroscience 23:1057-1061.

Parducz A, Loctin F, Babel-Guerin E, Dunant Y (1994) Exo-endocytotic activity during recovery from a brief tetanic stimulation: a role in calcium extrusion? Neuroscience 62:93-103.

Pezzati R, Grohovaz F (1999) The frog neuromuscular junction revisited after quick-freezing-freeze-drying: ultrastructure, immunogold labelling and high resolution calcium mapping. Philos Trans R Soc Lond B Biol Sci 354:373-378.

Poskanzer KE, Marek KW, Sweeney ST, Davis GW (2003) Synaptotagmin I is necessary for compensatory synaptic vesicle endocytosis in vivo. Nature 426:559-563.

Rahamimoff R, DeRiemer SA, Ginsburg S, Kaiserman I, Sakmann B, Shapira H, Yakir N (1990) Ionic channels and proteins in synaptic vesicles: facts and speculations. J Bas Clin Physiol Pharmacol 1:7-17.

Raison S, Gillot I, Choine C, Pistone P, Pagnotta S, Laugier JP, Nicaise G (1999) Ca increase in secretory granules of stimulated mast cells. Cell Calcium 26:111-119.

Rephaeli A, Parsons SM (1982) Calmodulin stimulation of ${ }^{45} \mathrm{Ca}^{2+}$ transport and protein phosphorylation in cholinergic synaptic vesicles. Proc Natl Acad Sci USA 79:5783-5787.

Rosenmund C, Stevens CF (1997) The rate of aldehyde fixation of the exocytotic machinery in cultured hippocampal synapses. J Neurosci Methods 76:1-5.

Sabatini BL, Oertner TG, Svoboda K (2002) The life cycle of $\mathrm{Ca}^{2+}$ ions in dendritic spines. Neuron 33:439-452.

Siddiqi O, Benzer S (1976) Neurophysiological defects in temperaturesensitive paralytic mutants of Drosophila melanogaster. Proc Natl Acad Sci USA 73:3253-3257.

Suzuki S, Osanai M, Murase M, Suzuki N, Ito K, Shirasaki T, Narita K, Ohnuma K, Kuba K, Kijima H (2000) $\mathrm{Ca}^{2+}$ dynamics at the frog motor nerve terminal. Pflügers Arch 440:351-365.

Tank DW, Regehr WG, Delaney KR (1995) A quantitative analysis of presynaptic calcium dynamics that contribute to short-term enhancement. J Neurosci 15:7940-7952.

Umbach JA, Saitoe M, Kidokoro Y, Gundersen CB (1998) Attenuated influx of calcium ions at nerve endings of csp and shibire mutant Drosophila. J Neurosci 18:3233-3240.

van der Bliek M, Meyerowitz EM (1991) Dynamin-like protein encoded by the Drosophila shibire gene associated with vesicular traffic. Nature 351:411-414.

Winslow JL, Duffy SN, Charlton MP (1994) Homosynaptic facilitation of transmitter release in crayfish is not affected by mobile calcium chelators: implications for the residual ionized calcium hypothesis from electrophysiological and computational analyses. J Neurophysiol 72:1769-1793.

Woodbury DJ (1995) Evaluation of the evidence for ion channels in synaptic vesicles. Mol Membr Biol 12:165-171. 